every four hours. I spent hundreds of pounds on osteopath fees for a stiff neck and back. Three months later I went back to the surgery.

This time I saw a different doctor. I explained all my symptoms again, which took up to 10 minutes. I am always conscious of the workload of doctors, the time allowed for each appointment, and that if a patient is with a doctor for too long the appointment schedule is affected. This knowledge makes me hurry through an explanation of my symptoms. All in all, I saw four different doctors; until I ended up with the one who diagnosed my condition (underactive thyroid) and prescribed thyroxine. I have since felt completely well, but I regret the time it took to be diagnosed. I am now adamant that I will see only the doctor who diagnosed my condition and am prepared to wait, within reason, to ensure that I do.

Since childhood-I am now 44-I have had recurrent bouts of tonsillitis. I know the symptoms and the treatment well. My temperature increases to $104^{\circ} \mathrm{C}$, my throat becomes covered in ulcers, and I need antibiotics. If treated, I am well within three days. If left untreated, it may take me up to two weeks to recover. A doctor familiar with my character and medical history would know this. Yet I have lost count of the times I have been told that throat infections are caused by viruses, that viral infections are untreatable by antibiotics, and the dangers of antibiotics, and I have had to argue for a prescription.

The problem with lack of continuity in general practice is that the patient's character is not taken into account. Is he or she a malingerer or a whiner? Is he or she perhaps the person best qualified to understand and diagnose his or her own illness? What seems straightforward on paper may be less so in reality, and a busy doctor has little time to read a patient's notes comprehensively. This inevitably increases the consultation time and puts strain on the practice. It is also likely to make patients irritable and to affect their relationship with their doctors, making them more guarded than necessary.

What seems to work best-from an entirely subjective point of view-is a polyclinic, with its back up of specialist options, together with the opportunity to see the same doctor. If patients are offered no choice about this, they are likely to end up frustrated and resentful and feeling like just a number in a large machine. It is deflating to find a doctor distractedly flicking through your notes to try and gain a sense of your medical history. It is equally frustrating to have to answer the same questions asked just a week earlier, as the doctor tries to comes to terms with your condition and character.

\title{
Rapid virological surveillance of community influenza infection in general practice
}

William F Carman, Lesley A Wallace, Jacqueline Walker, Sheena McIntyre, Ahilya Noone, Peter Christie, James Millar, James D Douglas

West of Scotland Regional Virus Laboratory, Gartnavel General Hospital, Glasgow G12 0YN

William F Carman honorary consultant Lesley A Wallace postdoctoral research assistant

Jacqueline Walker medical laboratory scientific officer

Tweeddale Medical Practice, Fort William PH33 6EU Sheena McIntyre research nurse James D Douglas general practitioner

continued over

BMJ 2000;321:736-7
The annual outbreak of influenza in Scotland is monitored by sentinel general practices, which report influenza-like illness. We piloted real time virological surveillance to investigate whether polymerase chain reaction $(\mathrm{PCR})^{12}$ is useful for monitoring an outbreak while it is evolving; to compare PCR with two standard techniques-culture and serology; and to compare two media for submitting samples.

\section{Methods and results}

Six practices took part. Influenza-like illness was defined by using standard criteria. Combined nose and throat swabs were submitted in both lysis buffer ${ }^{3}$ and viral transport medium. Two serum samples were taken a minimum of three weeks apart. All samples were posted to the laboratory. Influenza A and $\mathrm{B}$ reverse transcription PCR was performed on both media. ${ }^{3}$ Primary rhesus monkey kidney cells (Biowhittaker, Wokingham) were used to isolate virus. Influenza A and B antibodies were measured using the complement fixation test.

Patients were aged 17 to 72 years (mean 50.5 years), comprising 104 women and 64 men. Samples were taken 1-21 (mean 5.3) days after onset of illness, although $84 \%$ of samples were taken within seven days of onset.

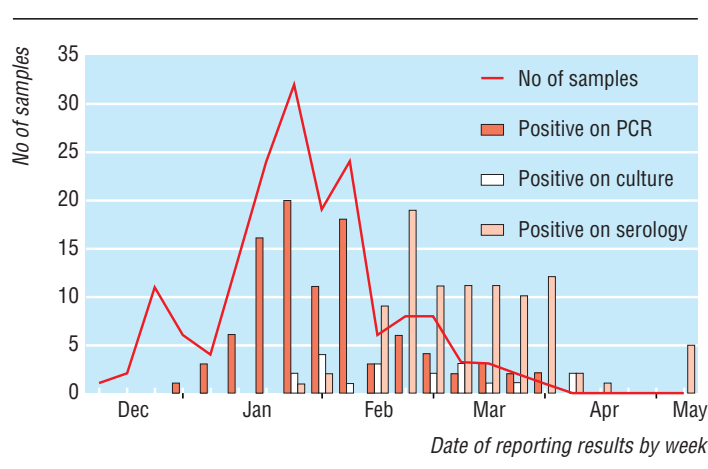

Date of arrival of samples (line graph) at the laboratory and dates of reporting results for polymerase chain reaction, virus culture, and serology (bar charts)

PCR results were available within 36 hours of sample arrival, culture took at least a week, and serology took a minimum of three weeks in this study (figure). Overall, $112(67 \%)$ patients had influenza infection that was confirmed by the laboratory. Of 168 samples, 97 were positive for PCR (57\% overall): 84 for influenza A and 13 for influenza B. Nineteen of these also had positive results by culture. Of 153 patients tested serologically, 94 (61\%) showed a rising or high $(\geqslant 128)$ titre. Fifteen patients with positive serology had negative results with PCR; 
nine of these had their swabs taken eight or more days after onset of illness. Excluding samples taken after eight days, the sensitivity of PCR compared with any positive diagnosis (PCR, serology, and culture) was 94.2\%. Conversely, 12 patients had positive results with PCR, but had negative results with serology. Thus, serology sensitivity compared with any positive result was $88.7 \%$.

An additional $10 \%$ of samples were positive by PCR in lysis buffer alone.

Five of 13 samples that were negative for influenza and that were submitted in the first two weeks of the study were later confirmed by PCR to be rhinovirus infections.

\section{Comment}

Real time surveillance using PCR with a rapid turnaround time confirms that influenza is circulating. As the PCR results were faxed back the next day, there was a stimulus to send in further samples. Results of serology and PCR correlated well, although serology took three weeks longer (figure). No false positives were generated by PCR. Culture was insensitive and slow because of the variation between batches of the primary cell line used in this laboratory. The time since onset of illness is critical for the sensitivity of virus isolation and PCR. In the late phase of illness, when results of culture and PCR were negative, there was already a high antibody titre.

Although culture is required to accumulate virus isolates for antigenic characterisation of the circulating viruses, PCR should now be the front line assay for diagnosis of influenza, even in non-specialist laboratories after initial training. It is clear that additional pathogens cause influenza-like illness, and the introduction of a multiplex PCR to test for a wider number of pathogens ${ }^{24}$ will considerably improve surveillance of the winter respiratory burden. New treatments for influenza strengthen the case for improved virological surveillance to alert clinicians to the cause of influenza-like illness and for rapid diagnosis and appropriate treatment of individual cases.

We acknowledge the hard work performed by the staff of the participating general practices.

Contributors: WFC, LAW, JDD, JM, AN, and PC designed and carried out the study. LAW and JW did the laboratory work. SM coordinated sample collection in all practices. LAW and WFC wrote the paper. WFC guarantees the paper.

Funding: The Scottish Centre for Infection and Environmental Health provided partial financial support.

Competing interests: None declared.

1 Atmar RL, Baxter BD, Dominguez EA, Taber LH. Comparison of reverse transcription-PCR with tissue culture and other rapid diagnostic assays for detection of type A influenza virus. J Clin Microbiol 1996;34:2604-6.

2 Stockton J, Ellis JS, Saville M, Clewley JP, Zambon MC. Multiplex PCR for typing and subtyping influenza and respiratory syncytial viruses. $J$ Clin Microbiol 1998:36:2990-5.

3 Wallace LA, McAulay KA, Douglas JDM, Elder AG, Stott DJ, Carman WF. Influenza diagnosis: from dark isolation into the molecular light. J Infect 1999;39:221-6.

4 Grondahl B, Puppe W, Hoppe A, Kuhne I, Weigl JA, Schmitt HJ. Rapid identification of nine microorganisms causing acute respiratory tract infections by single-tube multiplex reverse transcription-PCR: feasibility study. J Clin Microbiol 1999;37:1-7.

(Accepted 28 March 2000)

\title{
Clinical governance in primary care Participating in clinical governance
}

\author{
Mike Pringle
}

Earlier papers in this series have highlighted the collective nature of clinical governance in primary care and the central role of primary care groups, trusts, and practices. But definitions of clinical governance have also emphasised the responsibilities of individuals, highlighting the importance of lifelong learning by all clinicians and creating a clear obligation actively to manage poor professional performance when it is identified. ${ }^{1-3}$

This article will concentrate on the implications of clinical governance for individuals working in primary care. All primary care practitioners will have to develop systems for clinical governance. This includes pharmacists, opticians, and dentists, for whom the relative isolation of their practices can make such work difficult. ${ }^{4}$ The main focus of this paper will be on clinical governance in general practice.

The paper will explore the relation between clinical governance, continuing professional development, and revalidation. It will consider how an individual's learning and development can be linked to that of the practice as a whole. It will also consider the need to protect the public from unacceptable care and the need to manage poor performance.

\section{Summary points}

Clinical governance is intended to improve standards of care and at the same time to protect the public from unacceptable care

The move from continuing medical education for doctors to continuing professional development for the whole primary care team presents new challenges for multidisciplinary learning and performance monitoring

To deal with poor performance, clinical governance leaders will need skills to assess the nature of the problem, educational resources to deal with it, and managerial resources to facilitate the process

Participation in the activities of clinical governance will be an essential feature of revalidation
This is the

fourth in a series of five articles

Department of General Practice, Queen's Medical Centre, Nottingham NH7 2UH

Mike Pringle professor mike.pringle@ nottingham.ac.uk Series editor: Rebecca Rosen

BMJ 2000;321:737-40 